SB 603

. D47

Copy 1 



\section{HOW TEACHERS MAY USE PUBLICATIONS ON THE GONTROL OF DISEASES AND INSECT ENEMIES OF THE HOME GARDEN}

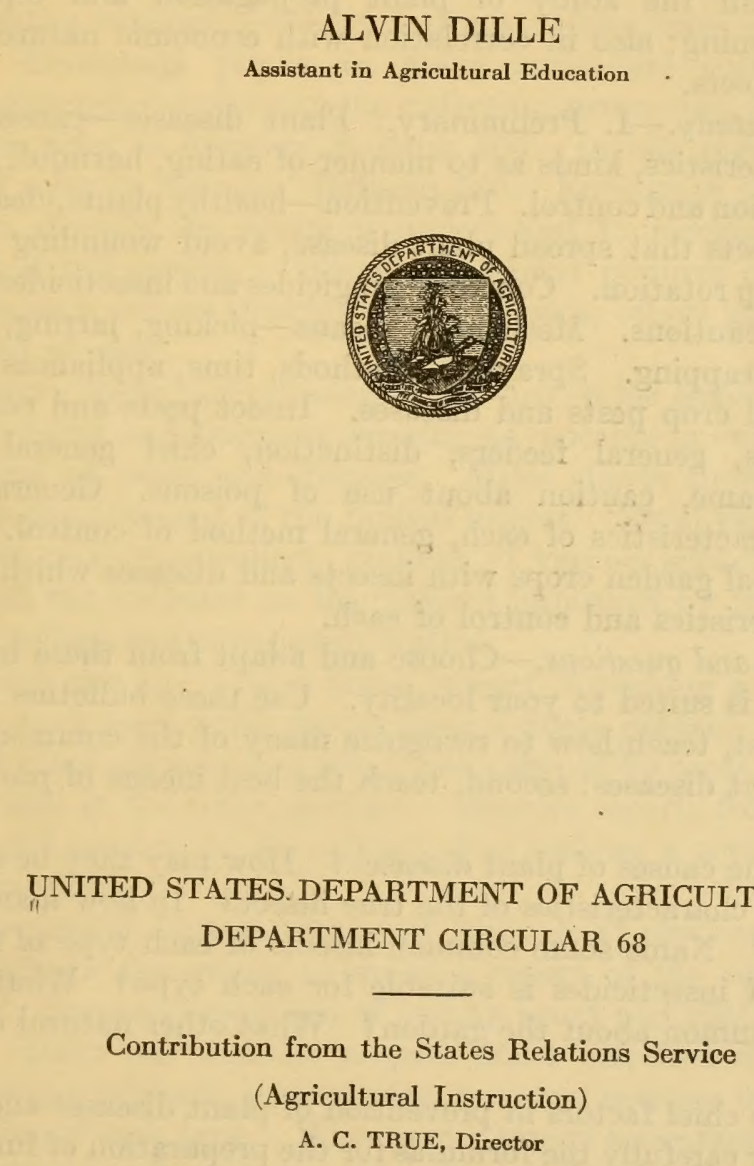

Assistant in Agricultural Education

Washington, D. C. 


\section{HOW TEACHERS MAY USE PUBLICATIONS ON THE CON- TROL OF DISEASES AND INSECT ENEMIES OF THE HOME GARDEN. ${ }^{1}$}

Range of use.-All garden sections of the United States.

Relation to the course of study.-These bulletins may be used in connection with the study of plant propagation and especially in home gardening; also in correlation with economic nature study and other subjects.

Topics for study.-I. Preliminary. Plant diseases-causes. Insects - characteristics, kinds as to manner of eating, harmful, useful.

II. Prevention and control. Prevention-healthy plants, clean seed, control of insects that spread plant disease, avoid wounding plants, sanitation, crop rotation. Control-fungicides and insecticides; preparation, use, cautions. Mechanical means-picking, jarring, brushing, beating, trapping. Spraying-methods, time, appliances.

III. General crop pests and diseases. Insect pests and controlchoice feeders, general feeders, distinction, chief general pests, control for same, caution about use of poisons. General crop diseases-characteristics of each, general method of control.

IV. Principal garden crops with insects and diseases which attack each, characteristics and control of each.

Suggestions and questions.-Choose and adapt from these bulletins material that is suited to your locality. Use these bulletins for two purposes: First, teach how to recognize many of the common insect pests and plant diseases; second, teach the best means of prevention and control.

What are the causes of plant diseases? How may they be spread? What are the characteristics of the true insect? In how many ways do they feed? Name some common insects of each type of feeders. What kind of insecticides is suitable for each type? What useful insects are common about the garden? What other natural enemies of insects?

Discuss the chief factors in prevention of plant diseases and insect pests. Study carefully the formulas for the preparation of fungicides and insecticides and note the cautions concerning their use. What

1 Including among others Farmers’ Bulletins Nos. 856, 868, 925, bulletins from State agricultural colleges and experiment stations, and extension circulars of the States Relations Service, United States Department of Agriculture.

$133953^{\circ}-19$

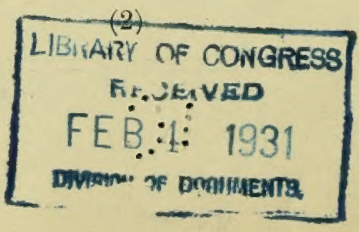


are the factors of successful spraying? Name the types of spraying and dusting appliances. (For a spray calendar suitable for your State, apply to your State agricultural college.) For garden use the bucket pumps, the small compressed-air sprayer, and the hand sprayer or small atomizer sprayer are best. These types of sprayers may usually be purchased of the local hardware dealer, and will frequently be loaned for school demonstration.

Name the types of injurious insects from the standpoint of their food plants. Make a list of the general feeders in your locality. What general type of control for these insects? Study the general crop diseases. Discuss those common to your community.

Illustrative material.-Collect and mount specimens of the garden insects: Encourage pupils to make individual collections. For specific directions concerning the collecting, preserving, and mounting of insects refer to Farmers' Bulletin 606. In like manner for plant material refer to Farmers' Bulletin 586. Encourage your pupils to learn to identify the common insects and to recognize the plant diseases of the garden. Collect and mount pictures of insects and plant diseases, others showing effects of each, others showing results of control of same.

Caution: Never risk releasing a new pest in the section.

Make charts and diagrams showing advantages in crop production by control of pests and diseases. Make charts showing different stages in development of the typical insects. From seed and manufacturers' catalogues collect pictures of various spraying machines. Collect all the bulletins on this subject published by the State agricultural college and experiment station.

Practical exercises.-As a home project furnishing a basis for the practice work each pupil should have a home garden. A first-hand study of plant diseases and insect pests should be made in the school gardens and in the home gardens. Require reports from the pupils in different sections of the district, thus making a sort of survey of plant enemies.

Give practical demonstrations of methods of prevention and control. Require the pupils to make a report of the results of such practice. Secure cooperation of county agent and State agricultural college. Have the students prepare under direction of the teacher the Bordeaux mixture, lime-sulphur mixture, and one or more of the insecticides of each type. When pupils report appearance of a garden disease or pest make a study of it and apply proper control. In each case emphasize that spraying for prevention, especially for plant diseases, is by far the best practice. Give practical demonstration on treating of seeds before planting. Teach importance of clean seed.

Correlations.-Oral or written reports upon observation or practice of insect or plant disease control make good exercises for 
language. If the work relates to home projects the reports should be written and a copy should be kept for permanent record. Compute money lost on any crop damaged by pests.

Booklets on the life history of one of the garden pests, illustrated by drawings showing different stages in development and accompanied by mounted specimens, afford good exercises in language and drawing.

The construction of charts showing different stages of insects and parts of diseased plants will not only furnish good drawing lessons but add to the illustrative material.

In case the insect is not native a report made concerning its native home, its introduction into the country, its spread, and attempts at control may be written up for a permanent record.

Have a record kept of insects and diseases observed in the district. List these separately with proper tabulations. The following forms are merely suggestive:

Garden insect pests.

\begin{tabular}{|c|c|c|c|c|c|c|}
\hline Insect. & $\begin{array}{c}\text { Stage of } \\
\text { development. }\end{array}$ & Kind of feeder. & Host. & Control. & When found. & In what garden. \\
\hline & & & & & & \\
\hline & & & & & & \\
\hline & & & & & & \\
\hline
\end{tabular}

Garden plant diseases.

\begin{tabular}{|c|c|c|c|c|c|}
\hline Host. & Disease. & $\begin{array}{l}\text { Part of plant } \\
\text { attacked. }\end{array}$ & Control. & When found. & In what garden. \\
\hline & & & & & \\
\hline & & & & & \\
\hline
\end{tabular}


LIBRARY OF CONGRESS

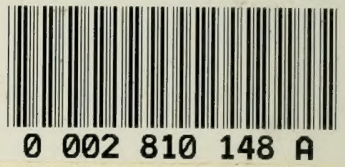

